\title{
Dendritic Cell Cancer Vaccines: From the Bench to the Bedside
}

\author{
Tamar Katz, Ph.D. ${ }^{1,2 *}$, Irit Avivi, M.D. ${ }^{1,2}$, Noam Benyamini, M.D. ${ }^{1}$, Jacalyn \\ Rosenblatt, M.D. ${ }^{3}$, and David Avigan, M.D. ${ }^{3}$ \\ ${ }^{\prime}$ Department of Hematology and Bone Marrow Transplantation, Rambam Health Care Campus, Haifa, \\ Israel; ' Bruce Rappaport Faculty of Medicine, Technion, Israel Institute of Technology, Haifa, Israel; and \\ ${ }^{3}$ Hematological Malignancies and Bone Marrow Transplantation, Beth Israel Deaconess Medical Center, \\ Harvard Medical School, Boston, MA, USA
}

\begin{abstract}
The recognition that the development of cancer is associated with acquired immunodeficiency, mostly against cancer cells themselves, and understanding pathways inducing this immunosuppression, has led to a tremendous development of new immunological approaches, both vaccines and drugs, which overcome this inhibition. Both "passive" (e.g. strategies relying on the administration of specific T cells) and "active" vaccines (e.g. peptide-directed or whole-cell vaccines) have become attractive immunological approaches, inducing cell death by targeting tumor-associated antigens. Whereas peptide-targeted vaccines are usually directed against a single antigen, whole-cell vaccines (e.g. dendritic cell vaccines) are aimed to induce robust responsiveness by targeting several tumor-related antigens simultaneously. The combination of vaccines with new immuno-stimulating agents which target "immunosuppressive checkpoints" (anti-CTLA4, PD-1, etc.) is likely to improve and maintain immune response induced by vaccination.
\end{abstract}

KEY WORDS: Cancer vaccines, dendritic cells, hematological malignancies, immunotherapy

\begin{abstract}
Abbreviations: Ab, antibody; APCs, antigen-presenting cells; CTLA-4, cytotoxic T-lymphocyte associated antigen 4; DCs, dendritic cells; HLA, human leukocyte antigen; HSCT, hematopoietic stem cell transplantation; IDO, indolamine2,3-dioxygenase; mAb, monoclonal antibodies; MDSC, myeloid derived suppressor cells; MHC, major histocompatibility complex; MM, multiple myeloma; PD-1, programmed death-1; PTLD, post-transplant proliferative disorders; TAP, transporter associated with antigen processing; TILs, tumor-infiltrating lymphocytes; Tregs, regulatory T cells.

Citation: Katz T, Avivi I, Benyamini N, Rosenblatt J, Avigan D. Dendritic Cell Cancer Vaccines: From the Bench to the Bedside. Rambam Maimonides Med J 2014;5 (4):eo024. doi:10.5041/RMMJ.10158

Copyright: (c) 2014 Katz et al. This is an open-access article. All its content, except where otherwise noted, is distributed under the terms of the Creative Commons Attribution License (http://creativecommons.org/licenses/by/3.0), which permits unrestricted use, distribution, and reproduction in any medium, provided the original work is properly cited.
\end{abstract}

Conflict of interest: No potential conflict of interest relevant to this article was reported.

* To whom correspondence should be addressed. E-mail: t_katz@rambam.health.gov.il 


\section{INTRODUCTION}

In a large proportion of patients, hematological malignancies remain incurable with conventional chemotherapy. The most promising new cancer treatment approach is immunotherapy that harnesses the immune system to fight cancer by inducing or suppressing immune responses.

The earliest evidence for the role of the immune response against cancer cells was provided in the work by William Coley, who injected Streptococcus pyogenes to sarcoma patients in an effort to reproduce spontaneous remissions observed in cancer patients developing erysipelas. Ten percent of these incurable non-resectable patients responded. ${ }^{1}$ Similar promising results obtained in several other studies led to the use of bacilli Calmette-Guérin (BCG) for cancer immunotherapy, which continues to be employed to the present day as an effective therapy against superficial bladder cancer. ${ }^{2}$

The immune system has the ability to identify and eliminate tumor cells on the basis of tumorspecific antigens in the process of "immuno-editing" that includes three phases: elimination, equilibrium, and escape. ${ }^{3}$ At the elimination phase, 4 tumor cells are efficiently detected and destroyed by the immune system. Tumor cells not completely eliminated by the immune system proceed to the equilibrium phase where the tumor persists but is not expanding. The escape phase begins when the balance between the immune response and the tumor moves towards tumor growth, which may be caused by immune exhaustion, inhibition, or occurrence of tumor cell variants that allow the tumor to evade the immune system.

The information regarding immune response to cancer remained controversial throughout the twentieth century; only with the development of mouse models has our understanding advanced significantly. For instance, a series of experiments demonstrated that mutant mice with severe combined immunodeficiency, lacking $\mathrm{T}$ and $\mathrm{B}$ lymphocytes, had a high tendency to develop lymphomas and carcinomas. 5 Furthermore, other studies have shown that mice injected with irradiated tumor cells became protected against lethal viable cells of the same tumor. ${ }^{6}$

Accordingly, studies in humans reported a high incidence of lymphomas and other malignancies in immunocompromised states.7,8 Patients undergoing solid organ or bone marrow transplantation were found to be at an increased risk of developing posttransplant lymphoproliferative disorders (PTLD), 9 and therefore discontinuation of immunosuppressive drugs potentially resulting in immunity reconstruction could contribute to successful management of these patients.

One of the earliest and most successful immunotherapies developed for hematological malignancies was hematopoietic stem cell transplantation (HSCT). While this procedure is associated with significant morbidity and mortality, it has been shown to prolong long-term disease-free survival as well as overall survival and can be curative in a subset of patients. This efficacy of HSCT is attributed to the graft-versus-disease effect mediated by allogeneic donor T cells. ${ }^{10}$ Another demonstration of the impressive immune reaction in the HSCT setting is the donor lymphocyte infusion that can eradicate post-transplant disease relapse. ${ }^{11}$

\section{PRIMARY MECHANISMS OF IMMUNE ESCAPE}

Although the immune system has a potential capability to recognize and attack cancer cells, tumor cells manage to escape immune recognition by employing different mechanisms which normally protect healthy tissues from autoimmune reactions. These mechanisms include inefficient processing and presentation of tumor antigens, up-regulation of negative co-stimulatory ligands which mediate $\mathrm{T}$ cell anergy, ${ }^{12}$ expansion of regulatory cells, and production of "immunosuppressive molecules," such as transforming growth factor $\beta$ (TGF- $\beta$ ), ${ }^{13}$ Fas ligand, ${ }^{14}$ and the immunosuppressive enzyme indolamine-2,3-dioxygenase (IDO). ${ }^{15}$ Tumor cells can also directly escape $\mathrm{T}$ cell recognition through down-regulating major histocompatibility complex (MHC) class I or disabling other components of antigen process. ${ }^{16}$

\section{Inefficient Processing and Presentation of Tumor Antigens}

Recognition of tumor-specific antigens is mediated by selected MHC molecules. Tumor cells can directly escape $\mathrm{T}$ cell recognition through down-regulation of either MHC class I, or tumor antigen expression.

Moreover, cancer-induced defects in human leukocyte antigen (HLA) or in other antigenprocessing molecules, like transporter associated with antigen processing (TAP), may also contribute to this immune escape. Additionally, cancer cells 
often induce secretion of "immunosuppressive" factors which interfere with dendritic cell maturation and function, leading to an inefficient $\mathrm{T}$ cell activation against tumor cells.

\section{Inhibitory T Cell Pathways}

The $\mathrm{T}$ cell receptor co-stimulatory pathways are important immune checkpoints involved in maintaining homeostasis of the immune system by regulating $\mathrm{T}$ cell activation.

One of the significant immune checkpoint receptors is cytotoxic T-lymphocyte associated antigen 4 (CTLA-4) expressed on T cells which down-regulates $\mathrm{T}$ cell activation aiming to limit damage to self-tissues. ${ }^{17}$ The expression of CTLA-4 on the $\mathrm{T}$ cell surface reduces the activation of $\mathrm{T}$ cells by competing with the $\mathrm{T}$ cell co-stimulatory receptor CD28 in binding to identical ligands CD8o and CD86 and delivering inhibitory signals to the $\mathrm{T}$ cell. ${ }^{18}$ Upon binding CTLA-4 arrests T cell activation by down-regulation of $\mathrm{CD} 4+\mathrm{T}$ helper cells and increase in immunosuppressive activity of $\mathrm{T}$ regulatory cells.

Tumor cells can exploit this pathway by expressing ligands for the CTLA-4 receptor on their surface. Blockade of CTLA-4 with specific monoclonal antibodies can shift the immune system balance toward T-cell activation, leading to tumor rejection. Both retrospective and prospective phase II and III studies have recently demonstrated a significant antitumor activity of the anti-CTLA-4 blocking antibody ipilimumab in advanced melanoma. ${ }^{19}$ The response rate in patients with advancedstage disease who failed previous therapies and had no other potential therapeutic opportunities approached $40 \%$ and was translated into an improved survival. ${ }^{20,21}$ Interestingly, response was accompanied by increase in lymphocyte count and a decrease in regulatory $\mathrm{T}$ cells (Tregs). ${ }^{21}$

Another key checkpoint pathway mediating tumor-induced immune suppression is the programmed death-1 (PD-1); PD-1 is a cell surface inhibitory receptor expressed on T cells, B cells, monocytes, and natural killer $\mathrm{T}$ cells, following activation. ${ }^{22}$ It has two ligands: PD-L1 (B7-H1) and PD-L2 (B7-DC), both expressed on antigen-presenting cells (APCs).23 The ligand PD-L1, thought to be the main mediator of PD-1-dependent immunosuppression, is also expressed on some non-hematopoietic cells. The interaction of PD-1 with its ligand inhibits T-cell receptor signaling, down-regulates the expression of some antiapoptotic molecules, and influences the cell cycle. ${ }^{24}$ The PD-1 pathway is an important regulator of induction and maintenance of peripheral tolerance involved in preventing tissue damage in chronic inflammation. ${ }^{25}$

The PD-1 pathway may have a key role in the interaction of tumor cells with the host immune response, and tumor cell PD-L1 expression may serve as a mechanism of adaptive immune resistance.

The ligand PD-L1 has been reported to be expressed on many different tumor cells. ${ }^{24}$ High PDL1 expression, at least in the solid tumor scenario, appears to correlate with increased tumor aggressiveness and high risk of death. ${ }^{26,27}$

Tumor-infiltrating lymphocytes (TILs) from patients with cancer, typically expressing PD-1, are characterized with an impaired antitumor functionality. ${ }^{28}$

Blockade of either PD-1 or its ligands with a specific monoclonal antibody enhances T-cell effector function, including cytolytic activity against tumor cells. Immune effects of the blockade have been shown in a variety of preclinical ${ }^{29}$ and clinical studies in both solid tumors (e.g. melanoma, lung cancer, etc.) ${ }^{30}$ and hematological malignancies. ${ }^{31} \mathrm{~A}$ recent study, investigating the safety and efficacy of anti-PD-1 antibody (Ab) in conjunction with rituximab in patients with relapsed follicular lymphoma, reported an encouraging safety profile and antilymphoma activity, with an overall response rate of $66 \%$, including $52 \%$ complete remissions. ${ }^{31}$

\section{Regulatory Immune Cells}

The tumor microenvironment is controlled by Tregs and other cell populations like myeloid-derived suppressor cells (MDSC) that create an immunosuppressive microenvironment and suppress antitumor effector $\mathrm{T}$ cells. Classic regulatory T cells are thymus-derived $\mathrm{CD}_{4}{ }^{+} \mathrm{CD} 25^{+} \mathrm{FOXP}_{3}{ }^{+} \mathrm{T}$ cells, which are responsible for inducing and maintaining peripheral tolerance through suppressing immune responses. ${ }^{32}$ Tregs also play a major role in tumor surveillance, suppressing an antitumor response both in tumor bed and systemically. Tregs are recruited to tumor sites, where they suppress antitumor cytotoxic responses. As most tumor antigens are self-antigens, Treg-mediated suppression has been proposed as a potential mechanism explaining the failure of antitumor immunity. Indeed, an 
increased number of Tregs in peripheral blood and tumor bed, often reported in both solid and hematooncological cancers, is associated with a worse prognosis. $33-35$

Depletion of Tregs or inhibition of their suppressive activity can enhance tumor immunity. This may be achieved using monoclonal antibodies (mAb) specific for cell surface molecules (CD25, Toll-like receptor, CTLA-4, GITR, OX4O, and folate receptor 4) that are predominantly expressed by Tregs or specifically able to modulate Treg function. 33 For instance, removal of Tregs by anti-CD25 $\mathrm{mAb}$ or toxin-conjugated anti-IL-2 (denileukin difitox) facilitates the activation and expansion of effector T cells that inhibit tumor growth in rodents. Since CD25 expression is also induced in activated effector T cells and IL-2 is required for the expansion of CD8 ${ }^{+}$T cells, treatment with anti-CD25 mAb or denileukin difitox may concurrently dampen effector T-cell responses. ${ }^{36}$

Preclinical data suggest Treg depletion to promote tumor regression.37-39 Development of new strategies aiming to attenuate selectively Tregs' immunosuppressive effect in the tumor microenvironment is needed.

As blockade of CTLA-4 is known to abrogate the suppressive activity of Tregs and improves tumor immunity, the combination of anti-CTLA- $4 \mathrm{mAb}$ and anti-GITR $m A b$ elicits a more potent antitumor response causing rejection of advanced stage tumors than does either mAb alone.

Another suppressive subset of cells is the heterogeneous population of MDSC that are expanded in cancer and have the capacity to suppress the immune response; MDSC are generated in the bone marrow in response to cancer-derived factors and are recruited to the tumor site by CCL2, CXCL12, and CXCL5. ${ }^{\circ}$ The MDSCs suppress the activation of $\mathrm{T}$ effector and natural killer cells and induce expansion of Tregs.

\section{VACCINE THERAPY FOR MYELOMA: REVERSING TUMOR-MEDIATED IMMUNE SUPPRESSION}

The development of multiple myeloma is associated with progressive immune dysregulation that promotes tumor growth and resistance.41,42 The immunologic milieu is characterized by the diminished activity of antigen-presenting cells and loss of effector cell function including deficiencies in $\mathrm{T}$ and natural killer (NK) cell function. Myeloma cells present antigens in the absence of co-stimulation and inflammatory signals, resulting in the inactivation of potentially reactive $\mathrm{T}$ cell populations. As such, antigens that are aberrantly expressed by the myeloma clone are unrecognized.43,44 Investigators have sought out strategies to reverse tumormediated immune suppression such that malignant cells are designated as foreign by immune-based mechanisms and eliminated. One such approach is the use of tumor vaccines to present tumor antigens effectively in the context of immune-activating signals. A primary strategy is through the use of potent antigen-presenting cells known as dendritic cells (DCs) that constitutively express co-stimulatory molecules and inflammatory cytokines necessary for the primary activation of immunity.

Dendritic cells represent a diverse network of antigen-presenting cells that play a prominent role in mediating immune responsiveness. ${ }^{45,46} \mathrm{Circu}-$ lating DC populations have been identified as myeloid and plasmacytoid in origin, characterized by the expression of CD11c and CD123, respectively. Myeloid DCs exhibit functional deficiencies in patients with myeloma that may impact their ability to elicit immunologic responses. 43 Plasmacytoid DCs have been identified as stromal elements in myeloma that help to mediate tolerance. In contrast, ex vivo-generated DCs from patients with myeloma exhibit a functionally active phenotype characterized by expression of co-stimulatory molecules and stimulatory cytokines and may serve as a vehicle for tumor vaccines. 47,48 Strategies to load tumor antigens include pulsing with peptides, proteins, or lysates, electroporation with tumor onto DCs including the use of whole-tumor cell or antigenspecific RNA, tumor-derived apoptotic bodies, transduction with viral vectors expressing tumor antigens, and whole-cell fusion between DCs and myeloma cells. $49-55$

\section{SINGLE ANTIGEN APPROACHES}

Myeloma-associated antigens have been identified that serve as potential targets for cellular immunotherapy. The idiotype protein represents a myelomaspecific antigen represented by the unique immunoglobulin gene arrangement of the malignant plasma cell..$^{6-61}$ Idiotype-based vaccines potentially induce a highly selective immune response but are potentially limited by uncertain immunogenicity and the challenge of isolating the unique $\mathrm{M}$ protein of each patient. In previously reported studies, 
vaccination with the idiotype protein in conjunction with GM-CSF or IL-12 was associated with antigenspecific $\mathrm{T}$ cell responses that correlated with improved outcomes. ${ }^{62}$ Responses have also been observed following vaccination with DCs pulsed with the idiotype protein and exposed to CD40L to induce maturation. ${ }^{63,64}$

Several shared antigens have been identified in myeloma cells that are uniquely or aberrantly expressed and serve as potential targets for immunotherapy. These include MUC1, WT1, PRAME, CYP1B1, and HSP96. ${ }^{65}-69$ A peptide-based vaccine for WT1 administered with immune adjuvant has been shown to elicit immunologic response in patients with hematological malignancies and a decrease in measures of disease. ${ }^{70}$ In a more recent study, WT1-specific T cells were detected in patients who had undergone allogeneic transplantation and correlated with durable remission. The cancer testis antigen, NY-ESO, demonstrates increased expression by plasma cells in the setting of advanced disease, creating an appealing target for immune-based therapy. ${ }^{71}$ Repetitive stimulation with DCs pulsed with an NY-ESO-derived peptide elicits a strong cytotoxic T lymphocyte (CTL) response in vitro, demonstrating an activated phenotype capable of lysing primary myeloma cells. Several other peptides which are highly expressed on myeloma cells and are important in the pathogenesis of the disease have been identified as potential immunogenic targets. Heteroclitic peptides derived from XBP1 (X-box-binding protein 1), CD138 (syndecan-1), and CS1 were shown alone or in combination to induce the expansion of myelomaspecific $\mathrm{T}$ cells with the capacity to lyse tumor cells. ${ }^{22-75} \mathrm{~A}$ trial is currently underway in which patients with smoldering myeloma undergo vaccination with combined myeloma-associated peptides in the context of immune adjuvant.

\section{WHOLE-CELL APPROACHES}

The use of whole-cell-derived antigens for vaccination may be advantageous by eliciting a broad polyclonal response that effectively targets the heterogeneity of the myeloma cell population. In one example, DCs pulsed with myeloma cell lysates induce myeloma-associated immunity, although the clinical efficacy was uncertain. 47 Other strategies that have been pursued include the use of whole-cell RNA, DNA, or apoptotic bodies for antigen loading onto DCs. 76,77
We have developed a vaccine model in which patient-derived myeloma cells are fused with autologous DCs such that a broad array of myeloma antigens are effectively presented in the context of enhanced co-stimulation. ${ }^{78-80}$ In a murine adenocarcinoma model, vaccination with $\mathrm{DC} /$ tumor fusions protected animals from an otherwise lethal challenge of tumor cells. Most significantly, vaccination was able to eradicate established disease in animals with advanced pulmonary metastases. Similarly, DC/multiple myeloma (MM ) cell fusions were effective in a syngeneic murine myeloma model, and therapeutic efficacy was further enhanced by coadministration of IL-12. In preclinical human studies, fusion of DCs and MM cells elicited the expansion of activated $\mathrm{T}$ cells that potently lysed autologous myeloma cells in vitro. We demonstrated that cell fusion induces DC maturation as manifested by increased expression of co-stimulatory molecules and maturation markers. ${ }^{81}$ Vaccine efficacy was further enhanced by exposure to inflammatory signals such as Toll-like receptor agonists. Sequential stimulation of $\mathrm{T}$ cells with $\mathrm{DC} /$ tumor fusions and ligation of the $\mathrm{T}$ cell costimulatory complex with anti-CD3/CD28 results in the dramatic expansion of tumor-specific lymphocytes. ${ }^{82}$

A phase I clinical trial was completed in which successive cohorts of patients with advanced myeloma underwent vaccination with escalating doses of autologous DC/MM fusions. ${ }^{83}$ Patients had undergone a median of four prior treatment regimens. Dendritic cells were generated from adherent mononuclear cells cultured with GM-CSF and IL-4 and matured with TNFa. Autologous myeloma cell preparations were obtained from bone marrow aspirates of patients with at least 20\% marrow involvement with tumor cells. Dendritic cells and myeloma cells underwent phenotypic characterization to identify markers unique to each population. Dendritic cells were subsequently fused with autologous myeloma cells by co-culture in the presence of polyethylene glycol. Fusion cells were quantified by determining the percentage of cells that coexpressed unique DC and myeloma antigens. Vaccine production was feasible with achievement of the planned dose escalation up to a dose of $4 \times 10^{6}$ fusion cells. Patients underwent serial vaccination in conjunction with GM-CSF. Vaccine-associated toxicity consisted of transient grade 1-2 vaccine site reactions most commonly, while clinically significant autoimmunity was not observed. Biopsy of the 
vaccine bed demonstrated a dense infiltrate of CD8+ $\mathrm{T}$ cells consistent with $\mathrm{T}$ cell expansion occurring at the site of vaccination. Vaccination resulted in the expansion of myeloma-specific T cells in a majority of patients as manifested by the percent of $\mathrm{CD} 4$ and/or CD8 T cells expressing IFN $\gamma$ following $e x$ vivo exposure to autologous tumor lysate. Humoral responses directed against myeloma-associated targets were documented by SEREX analysis. Of note, $66 \%$ of patients demonstrated a period of disease stability ranging from several months to greater than 2 years after vaccination.

\section{VACCINATION IN CONJUNCTION WITH AUTOLOGOUS TRANSPLANTATION}

While vaccination induced anti-myeloma immunity in patients with advanced disease, we postulated that clinical efficacy was more likely in the setting of minimal disease in which tumor-mediated disruption of cellular immunity is less pronounced.

In animal models, the period of lymphopoietic reconstitution is associated with enhanced responsiveness to tumor vaccines due to the relative depletion of regulatory $\mathrm{T}$ cells and the increased presence of tumor reactive clones. Of note, vaccination with idiotype pulsed antigen-presenting cells post-transplant was associated with improved progression-free survival as compared to a historical control cohort.59 Based on these studies, we have conducted a phase II study in which patients with myeloma underwent vaccination with $\mathrm{DC} / \mathrm{MM}$ fusions in conjunction with autologous transplant. 84 Patients underwent vaccine production during the period of pre-transplant induction therapy. A majority of the patients underwent vaccination following post-transplant hematopoietic recovery, while a small cohort underwent pre-transplant vaccination with post-transplant boosting. Vaccination was well tolerated without evidence of clinically significant autoimmunity or impact on post-transplant engraftment. While general measures of cellular immunity were depressed following transplant, a paradoxical increase in myeloma-specific $\mathrm{T}$ cells was observed that was further boosted following vaccination. In the cohort of patients undergoing post-transplant vaccination alone, $29 \%$ of patients achieved complete remission within the first 100 days following transplant. Following vaccination, between day 100 and 1 year post-transplant, $54 \%$ achieved complete remission, suggesting that the induction of myeloma-specific immunity was associated with the targeting of posttransplant minimal residual disease.

\section{IMMUNOMODULATORY THERAPY AND VACCINATION}

Immunomodulatory agents such as lenalidomide and pomalidomide have demonstrated significant efficacy in patients with myeloma through a variety of mechanisms, including direct cytotoxicity, inhibition of stromal myeloma cell interactions, and impact on anti-myeloma immunity. ${ }^{85,86}$ As these agents are thought to enhance the immunologic environment in patients with myeloma, there is considerable interest in combining these agents with tumor vaccines. Lenalidomide has been shown to augment NK cell function. ${ }^{87}$ We demonstrated that lenalidomide decreases PD-1 expression by T cells and polarizes $\mathrm{T}$ cell towards a Th1 as compared to a Th2 phenotype after stimulation with DC/tumor fusions. ${ }^{88}$ Previous studies have demonstrated that lenalidomide enhances response to the Pneumovax vaccine. 89 Based on these findings, a multicenter phase II randomized trial is being initiated by the Clinical Trials Network Cooperative group in which patients will receive post-transplant lenalidomide maintenance alone or in conjunction with serial vaccination with $\mathrm{DC} /$ myeloma fusions.

The negative co-stimulatory molecules CTLA-4 and PD-L1/PD-1 are critical mediators of tumormediated immune suppression and tolerance, and antibodies that block their function have become a major new area of cancer therapeutics. ${ }^{22,90}$ Blockade of CTLA-4 has demonstrated activity via activation of cell-mediated immunity and has received approval by the FDA for patients with recurrent melanoma. Blockade of PD-1 has been shown to induce durable disease regression in a subset of patients with melanoma and renal and non-small lung cancer, and is currently being studied in patients with hematological malignancies. In a phase II trial, patients with recurrent lymphoma underwent serial infusions with PD-1 antibody following autologous transplantation. Investigators are now examining the potential synergy between checkpoint blockade and vaccine therapy.

We have demonstrated that PD-L1 is strongly expressed by human myeloma cell lines as well as patient-derived samples. Increased expression of PD-1 is seen on circulating T cells in patients with active disease. We have shown that PD-1 blockade augments the efficacy of the DC/MM fusion vaccine in vitro as manifested by increased $\mathrm{T}$ cell expression of IFN $\gamma$, decreased expansion of regulatory $\mathrm{T}$ cells, and enhanced lysis of myeloma targets. ${ }^{91}$ Based on 
these findings, a clinical trial is now underway examining the efficacy of a PD-1 antibody alone or in conjunction with the DC/MM fusion vaccine following autologous transplantation. Preliminary results have demonstrated that post-transplant treatment with PD-1 antibody resulted in the expansion of myeloma-specific T cells and antigenspecific responses against MUC1, WT1, PRAME, NYESO, and survivin in the bone marrow and peripheral blood. ${ }^{2}$

\section{DENDRITIC CELL/TUMOR FUSION VACCINATION FOR PATIENTS WITH ACUTE MYELOID LEUKEMIA}

Given the findings in myeloma, we have explored the potential role of fusion cell vaccination in patients with acute myeloid leukemia. The potential role of cellular immunotherapy in targeting acute myeloid leukemia cells is highlighted by the observation that a subset of patients are rendered diseasefree following allogeneic transplantation due to the graft-versus-leukemia effect mediated by alloreactive $\mathrm{T}$ cells. We are conducting a clinical trial in which patients with active disease undergo collection of leukemia cells. Those patients who achieve remission subsequently undergo vaccine generation and serial vaccination. In preliminary findings, vaccination was associated with the induction of leukemia-specific immunity as manifested by the expansion of tumor-reactive lymphocytes and leukemia antigen-specific $\mathrm{T}$ cells. In the initial cohort of treated patients with a median age of $66,70 \%$ have remained in remission with a mean follow-up of 3 years.

In conclusion, tumors frequently interfere with the development and function of immune responses.

Cancer immunotherapy aims to employ the power and specificity of the immune system for the treatment of malignancy. Studies exploring immune combinations are ongoing, and new immunological approaches are under development.

\section{REFERENCES}

1. Coley WB. The treatment of malignant tumors by repeated inoculations of erysipelas. With a report of ten original cases. 1893. Clin Orthop Relat Res 1991;(262):3-11.

2. Kamat AM, Lamm DL. Immunotherapy for bladder cancer. Curr Urol Rep 2001;2:62-9. Full Text
3. Dunn GP, Old LJ, Schreiber RD. The three Es of cancer immunoediting. Annu Rev Immunol 2004;22: 329-60. Full Text

4. Burnet FM. Immunological aspects of malignant disease. Lancet 1967;1:1171-4. Full Text

5. Bosma GC, Custer RP, Bosma MJ. A severe combined immunodeficiency mutation in the mouse. Nature 1983;301:527-30. Full Text

6. Klein G, Sjogren HO, Klein E, Hellstrom KE. Demonstration of resistance against methylcholanthrene-induced sarcomas in the primary autochthonous host. Cancer Res 1960;20:1561-72.

7. Penn I. Tumors of the immunocompromised patient. Annu Rev Med 1988;39:63-73. Full Text

8. Roithmaier S, Haydon AM, Loi S, et al. Incidence of malignancies in heart and/or lung transplant recipients: a single-institution experience. J Heart Lung Transplant 2007;26:845-9. Full Text

9. Opelz G, Henderson R. Incidence of non-Hodgkin lymphoma in kidney and heart transplant recipients. Lancet 1993;342:1514-16. Full Text

10. Weiden PL, Sullivan KM, Flournoy N, et al. Antileukemic effect of chronic graft-versus-host disease: contribution to improved survival after allogeneic marrow transplantation. N Engl J Med 1981;304:1529-33. Full Text

11. Kolb HJ, Schattenberg A, Goldman JM, et al. Graftversus-leukemia effect of donor lymphocyte transfusions in marrow grafted patients. Blood 1995;86: 2041-50.

12. Yaguchi T, Sumimoto H, Kudo-Saito C, et al. The mechanisms of cancer immunoescape and development of overcoming strategies. Int J Hematol 2011; 93:294-300. Full Text

13. Teicher BA. Transforming growth factor-beta and the immune response to malignant disease. Clin Cancer Res 2007;13:6247-51. Full Text

14. Houston A, Bennett MW, O'Sullivan GC, et al. Fas ligand mediates immune privilege and not inflammation in human colon cancer, irrespective of TGF-beta expression. Br J Cancer 2003;89:1345-51. Full Text

15. Muller AJ, Prendergast GC. Indoleamine 2,3dioxygenase in immune suppression and cancer. Curr Cancer Drug Targets 2007;7:31-40. Full Text

16. Garrido F, Ruiz-Cabello F, Cabrera T, et al. Implications for immunosurveillance of altered HLA class I phenotypes in human tumours. Immunol Today 1997;18:89-95. Full Text

17. Fife BT, Bluestone JA. Control of peripheral T-cell tolerance and autoimmunity via the CTLA-4 and PD- 
1 pathways. Immunol Rev 2008;224:166-82. Full Text

18. Parry RV, Chemnitz JM, Frauwirth KA, et al. CTLA-4 and PD-1 receptors inhibit T-cell activation by distinct mechanisms. Mol Cell Biol 2005;25:9543-53. Full Text

19. Hodi FS, O'Day SJ, McDermott DF, et al. Improved survival with ipilimumab in patients with metastatic melanoma. N Engl J Med 2010;363:711-23. Full Text

20. Luke JJ, Callahan MK, Postow MA, et al. Clinical activity of ipilimumab for metastatic uveal melanoma: a retrospective review of the Dana-Farber Cancer Institute, Massachusetts General Hospital, Memorial Sloan-Kettering Cancer Center, and University Hospital of Lausanne experience. Cancer 2013;119:3687-95.

21. Simeone E, Gentilcore G, Giannarelli D, et al. Immunological and biological changes during ipilimumab treatment and their potential correlation with clinical response and survival in patients with advanced melanoma. Cancer Immunol Immunother 2014;63:675-83. Full Text

22. Keir ME, Butte MJ, Freeman GJ, Sharpe AH. PD-1 and its ligands in tolerance and immunity. Annu Rev Immunol 2008;26:677-704. Full Text

23. Latchman Y, Wood CR, Chernova T, et al. PD-L2 is a second ligand for PD-1 and inhibits T cell activation. Nat Immunol 2001;2:261-8. Full Text

24. McDermott DF, Atkins MB. PD-1 as a potential target in cancer therapy. Cancer Med 2013;2:662-73.

25. Topalian SL, Drake CG, Pardoll DM. Targeting the PD-1/B7-H1(PD-L1) pathway to activate anti-tumor immunity. Curr Opin Immunol 2012;24:207-12. Full $\underline{\text { Text }}$

26. Thompson RH, Gillett MD, Cheville JC, et al. Costimulatory B7-H1 in renal cell carcinoma patients: indicator of tumor aggressiveness and potential therapeutic target. Proc Natl Acad Sci U S A 2004; 101:17174-9. Full Text

27. Hamanishi J, Mandai M, Iwasaki M, et al. Programmed cell death 1 ligand 1 and tumor-infiltrating CD8+ $\mathrm{T}$ lymphocytes are prognostic factors of human ovarian cancer. Proc Natl Acad Sci U S A 2007;104: 3360-5. Full Text

28. Thompson RH, Dong H, Lohse CM, et al. PD-1 is expressed by tumor-infiltrating immune cells and is associated with poor outcome for patients with renal cell carcinoma. Clin Cancer Res 2007;13:1757-61. Full Text

29. Zhou Q, Xiao H, Liu Y, et al. Blockade of programmed death-1 pathway rescues the effector function of tumor-infiltrating $\mathrm{T}$ cells and enhances the antitumor efficacy of lentivector immunization. $\mathrm{J}$ Immunol 2010;185:5082-92. Full Text

30. Forde PM, Reiss KA, Zeidan AM, Brahmer JR. What lies within: novel strategies in immunotherapy for non-small cell lung cancer. Oncologist 2013;18:120313. Full Text

31. Westin JR, Chu F, Zhang M, et al. Safety and activity of PD1 blockade by pidilizumab in combination with rituximab in patients with relapsed follicular lymphoma: a single group, open-label, phase 2 trial. Lancet Oncol 2014;15:69-77. Full Text

32. Shevach EM. Fatal attraction: tumors beckon regulatory T cells. Nat Med 2004;10:900-1. Full Text

33. Nishikawa H, Sakaguchi S. Regulatory $\mathrm{T}$ cells in tumor immunity. Int J Cancer. 2010;127:759-67.

34. Tang Y, Xu X, Guo S, et al. An increased abundance of tumor-infiltrating regulatory $T$ cells is correlated with the progression and prognosis of pancreatic ductal adenocarcinoma. PLoS One 2014;9:e91551.

35. Curiel TJ, Coukos G, Zou L, et al. Specific recruitment of regulatory $\mathrm{T}$ cells in ovarian carcinoma fosters immune privilege and predicts reduced survival. Nat Med 2004;10:942-9. Full Text

36. Dannull J, Su Z, Rizzieri D, et al. Enhancement of vaccine-mediated antitumor immunity in cancer patients after depletion of regulatory T cells. J Clin Invest 2005;115:3623-33. Full Text

37. Forde PF, Sadadcharam M, Hall LJ, et al. Enhancement of electroporation facilitated immunogene therapy via T-reg depletion. Cancer Gene Ther 2014;21:349-54. Full Text

38. Abu-Eid R, Samara RN, Ozbun L, et al. Selective inhibition of regulatory $\mathrm{T}$ cells by targeting $\mathrm{PI}_{3} \mathrm{~K}-\mathrm{Akt}$ pathway. Cancer Immunol Res 2014 Jul 30. [Epub ahead of print]

39. Jarry U, Donnou S, Vincent M, et al. Treg depletion followed by intracerebral CpG-ODN injection induce brain tumor rejection. J Neuroimmunol 2014;267: 35-42. Full Text

40. Sawanobori Y, Ueha S, Kurachi M, et al. Chemokinemediated rapid turnover of myeloid-derived suppressor cells in tumor-bearing mice. Blood 2008;111: 5457-66. Full Text

41. Pratt G, Goodyear O, Moss P. Immunodeficiency and immunotherapy in multiple myeloma. Br J Haematol 2007;138:563-79. Full Text

42. Spisek R, Kukreja A, Chen LC, et al. Frequent and specific immunity to the embryonal stem cellassociated antigen SOX2 in patients with monoclonal gammopathy. J Exp Med 2007;204:831-40. Full Text 
43. Racanelli V, Leone P, Frassanito MA, et al. Alterations in the antigen processing-presenting machinery of transformed plasma cells are associated with reduced recognition by $\mathrm{CD} 8+\mathrm{T}$ cells and characterize the progression of MGUS to multiple myeloma. Blood 2010;115:1185-93. Full Text

44. Giannopoulos K, Kaminska W, Hus I, Dmoszynska A. The frequency of $\mathrm{T}$ regulatory cells modulates the survival of multiple myeloma patients: detailed characterisation of immune status in multiple myeloma. Br J Cancer 2012;106:546-52. Full Text

45. Avigan D. Dendritic cells: development, function and potential use for cancer immunotherapy. Blood Rev 1999;13:51-64. Full Text

46. Avigan D, Rosenblatt J, Kufe D. Dendritic/tumor fusion cells as cancer vaccines. Semin Oncol 2012; 39:287-95. Full Text

47. Lee JJ, Choi BH, Kang HK, et al. Induction of multiple myeloma-specific cytotoxic $\mathrm{T}$ lymphocyte stimulation by dendritic cell pulsing with purified and optimized myeloma cell lysates. Leuk Lymphoma 2007;48:2022-31. Full Text

48. Yang DH, Park JS, Jin CJ, et al. The dysfunction and abnormal signaling pathway of dendritic cells loaded by tumor antigen can be overcome by neutralizing VEGF in multiple myeloma. Leuk Res 2009;33:66570. Full Text

49. Albert ML, Sauter B, Bhardwaj N. Dendritic cells acquire antigen from apoptotic cells and induce class I-restricted CTLs. Nature 1998;392:86-9. Full Text

50. Weiner LM, Surana R, Wang S. Monoclonal antibodies: versatile platforms for cancer immunotherapy. Nat Rev Immunol 2010;10:317-27. Full Text

51. Wen YJ, Min R, Tricot G, et al. Tumor lysate-specific cytotoxic $\mathrm{T}$ lymphocytes in multiple myeloma: promising effector cells for immunotherapy. Blood 2002;99:3280-5. Full Text

52. Dembic Z, Schenck K, Bogen B. Dendritic cells purified from myeloma are primed with tumor-specific antigen (idiotype) and activate CD4+ T cells. Proc Natl Acad Sci U S A 2000;97:2697-702. Full Text

53. Signori E, Iurescia $S$, Massi E, et al. DNA vaccination strategies for anti-tumour effective gene therapy protocols. Cancer Immunol Immunother 2010;59: 1583-91. Full Text

54. Spisek R, Chevallier P, Morineau N, et al. Induction of leukemia-specific cytotoxic response by crosspresentation of late-apoptotic leukemic blasts by autologous dendritic cells of nonleukemic origin. Cancer Res 2002;62:2861-8.
55. Gulley JL, Arlen PM, Tsang KY, et al. Pilot study of vaccination with recombinant CEA-MUC-1-TRICOM poxviral-based vaccines in patients with metastatic carcinoma. Clin Cancer Res 2008;14:3060-9. Full $\underline{\text { Text }}$

56. O'Neill DW, Adams S, Bhardwaj N. Manipulating dendritic cell biology for the active immunotherapy of cancer. Blood 2004;104:2235-46. Full Text

57. Osterborg A, Yi Q, Henriksson L, et al. Idiotype immunization combined with granulocyte-macrophage colony-stimulating factor in myeloma patients induced type I, major histocompatibility complexrestricted, CD8- and CD4-specific T-cell responses. Blood 1998;91:2459-66.

58. Zahradova L, Mollova K, Ocadlikova D, et al. Efficacy and safety of Id-protein-loaded dendritic cell vaccine in patients with multiple myeloma--phase II study results. Neoplasma 2012;59:440-9. Full Text

59. Lacy MQ, Mandrekar S, Dispenzieri A, et al. Idiotypepulsed antigen-presenting cells following autologous transplantation for multiple myeloma may be associated with prolonged survival. Am J Hematol 2009; 84:799-802. Full Text

6o. Reichardt VL, Milazzo C, Brugger W, et al. Idiotype vaccination of multiple myeloma patients using monocyte-derived dendritic cells. Haematologica 2003;88:1139-49.

61. Titzer S, Christensen O, Manzke O, et al. Vaccination of multiple myeloma patients with idiotype-pulsed dendritic cells: immunological and clinical aspects. $\mathrm{Br}$ J Haematol 2000;108:805-16. Full Text

62. Hansson L, Abdalla AO, Moshfegh A, et al. Long-term idiotype vaccination combined with interleukin-12 (IL-12), or IL-12 and granulocyte macrophage colonystimulating factor, in early-stage multiple myeloma patients. Clin Cancer Res 2007;13:1503-10. Full Text

63. Yi Q, Szmania S, Freeman J, et al. Optimizing dendritic cell-based immunotherapy in multiple myeloma: intranodal injections of idiotype-pulsed CD40 ligand-matured vaccines led to induction of type-1 and cytotoxic T-cell immune responses in patients. Br J Haematol 2010;150:554-64. Full Text

64. Wen YJ, Ling M, Bailey-Wood R, Lim SH. Idiotypic protein-pulsed adherent peripheral blood mononuclear cell-derived dendritic cells prime immune system in multiple myeloma. Clin Cancer Res 1998;4:957-62.

65. Takahashi T, Makiguchi Y, Hinoda Y, et al. Expression of MUC1 on myeloma cells and induction of HLA-unrestricted CTL against MUC1 from a multiple myeloma patient. J Immunol 1994;153: 2102-9. 
66. Szmania S, Tricot G, van Rhee F. NY-ESO-1 immunotherapy for multiple myeloma. Leuk Lymphoma 2006;47:2037-48. Full Text

67. Hatta Y, Takeuchi J, Saitoh T, et al. WT1 expression level and clinical factors in multiple myeloma. J Exp Clin Cancer Res 2005;24:595-9.

68. van Rhee F, Szmania SM, Zhan F, et al. NY-ESO-1 is highly expressed in poor-prognosis multiple myeloma and induces spontaneous humoral and cellular immune responses. Blood 2005;105:3939-44. Full Text

69. Pellat-Deceunynck C, Mellerin MP, Labarriere N, et al. The cancer germ-line genes MAGE-1, MAGE-3 and PRAME are commonly expressed by human myeloma cells. Eur J Immunol 2000;30:803-9. Full Text

70. Yasukawa M, Fujiwara H, Ochi T, et al. Clinical efficacy of WT1 peptide vaccination in patients with acute myelogenous leukemia and myelodysplastic syndrome. Am J Hematol 2009;84:314-15. Full Text

71. Batchu RB, Moreno AM, Szmania SM, et al. Protein transduction of dendritic cells for NY-ESO-1-based immunotherapy of myeloma. Cancer Res 2005; 65:10041-9. Full Text

72. Bae J, Smith R, Daley J, et al. Myeloma-specific multiple peptides able to generate cytotoxic $\mathrm{T}$ lymphocytes: a potential therapeutic application in multiple myeloma and other plasma cell disorders. Clin Cancer Res 2012;18:4850-60. Full Text

73. Bae J, Song W, Smith R, et al. A novel immunogenic CS1-specific peptide inducing antigen-specific cytotoxic T lymphocytes targeting multiple myeloma. Br J Haematol 2012;157:687-701. Full Text

74. Bae J, Tai YT, Anderson KC, Munshi NC. Novel epitope evoking CD138 antigen-specific cytotoxic T lymphocytes targeting multiple myeloma and other plasma cell disorders. Br J Haematol 2011;155:34961. Full Text

75. Bae J, Carrasco R, Lee AH, et al. Identification of novel myeloma-specific XBP1 peptides able to generate cytotoxic $\mathrm{T}$ lymphocytes: a potential therapeutic application in multiple myeloma. Leukemia 2011;25:1610-19. Full Text

76. Milazzo C, Reichardt VL, Muller MR, et al. Induction of myeloma-specific cytotoxic $\mathrm{T}$ cells using dendritic cells transfected with tumor-derived RNA. Blood 2003;101:977-82. Full Text

77. Qian J, Wang S, Yang J, et al. Targeting heat shock proteins for immunotherapy in multiple myeloma: generation of myeloma-specific CTLs using dendritic cells pulsed with tumor-derived gp96. Clin Cancer Res 2005;11:8808-15. Full Text
78. Gong J, Chen D, Kashiwaba M, Kufe D. Induction of antitumor activity by immunization with fusions of dendritic and carcinoma cells. Nat Med 1997;3:55861. Full Text

79. Raje N, Hideshima T, Davies FE, et al. Tumour cell/dendritic cell fusions as a vaccination strategy for multiple myeloma. Br J Haematol 2004;125:343-52. Full Text

80. Gong J, Koido S, Chen D, et al. Immunization against murine multiple myeloma with fusions of dendritic and plasmacytoma cells is potentiated by interleukin 12. Blood 2002;99:2512-17. Full Text

81. Vasir B, Borges $\mathrm{V}, \mathrm{Wu} \mathrm{Z}$, et al. Fusion of dendritic cells with multiple myeloma cells results in maturation and enhanced antigen presentation. $\mathrm{Br} \mathrm{J}$ Haematol 2005;129:687-700. Full Text

82. Rosenblatt J, Wu Z, Vasir B, et al. Generation of tumor-specific T lymphocytes using dendritic cell/ tumor fusions and anti-CD3/CD28. J Immunother 2010;33:155-66. Full Text

83. Rosenblatt J, Vasir B, Uhl L, et al. Vaccination with dendritic cell/tumor fusion cells results in cellular and humoral antitumor immune responses in patients with multiple myeloma. Blood 2011;117:393402. Full Text

84. Rosenblatt J, Avivi I, Vasir B, et al. Vaccination with dendritic cell/tumor fusions following autologous stem cell transplant induces immunologic and clinical responses in multiple myeloma patients. Clin Cancer Res 2013;19:3640-8. Full Text

85. Galustian C, Meyer B, Labarthe MC, et al. The anticancer agents lenalidomide and pomalidomide inhibit the proliferation and function of T regulatory cells. Cancer Immunol Immunother 2009;58:103345. Full Text

86. Quach H, Ritchie D, Stewart AK, et al. Mechanism of action of immunomodulatory drugs (IMiDS) in multiple myeloma. Leukemia 2010;24:22-32. Full $\underline{\text { Text }}$

87. Benson DM Jr, Bakan CE, Zhang S, et al. IPH2101, a novel anti-inhibitory KIR antibody, and lenalidomide combine to enhance the natural killer cell versus multiple myeloma effect. Blood 2011;118:6387-91. Full Text

88. Luptakova K, Rosenblatt J, Glotzbecker B, et al. Lenalidomide enhances anti-myeloma cellular immunity. Cancer Immunol Immunother 2013;62:3949. Full Text

89. Noonan K, Rudraraju L, Ferguson A, et al. Lenalidomide-induced immunomodulation in multiple myeloma: impact on vaccines and antitumor responses. Clin Cancer Res 2012;18:1426-34. Full Text 
90. Barber DL, Wherry EJ, Masopust D, et al. Restoring function in exhausted CD8 T cells during chronic viral infection. Nature 2006;439:682-7. Full Text

91. Rosenblatt J, Glotzbecker B, Mills H, et al. PD-1 blockade by CT-011, anti-PD-1 antibody, enhances ex vivo T-cell responses to autologous dendritic cell/ myeloma fusion vaccine. J Immunother 2011;34: 409-18. Full Text
92. Reichardt VL, Okada CY, Liso A, et al. Idiotype vaccination using dendritic cells after autologous peripheral blood stem cell transplantation for multiple myeloma--a feasibility study. Blood 1999;93: 2411-19. 